\title{
An Unprecedented Straightforward Synthesis of Chiral Pyrrolo[3,4-b]quinolone and Pyrrolo[3,2-b]quinolone Backbones Starting from trans-4-Hydroxy-L-proline
}

\author{
Sébastien Comesse and Adam Daïch \\ Laboratoire de Chimie, URCOM, EA 3221, FR CNRS 3038, Normandie Université, Université du Havre, \\ UFR Sciences et Techniques, 25 rue Philippe Lebon, 76058 Le Havre Cedex, France
}

Correspondence should be addressed to Sébastien Comesse; sebastien.comesse@univ-lehavre.fr

Received 2 November 2015; Accepted 29 December 2015

Academic Editor: Marco Radi

Copyright (C) 2016 S. Comesse and A. Daïch. This is an open access article distributed under the Creative Commons Attribution License, which permits unrestricted use, distribution, and reproduction in any medium, provided the original work is properly cited.

The straightforward synthesis of pyrrolo[3,4-b]quinolone and pyrrolo[3,2-b]quinolone backbones, which can be found in molecules exhibiting anticancer activities, is presented. The key step of the process is an efficient and unprecedented Friedländer condensation between an oxoproline carbamate, obtained in 3 steps and good yield starting from commercially available and relatively cheap trans-4-hydroxy-L-proline, and various 2-amino-substituted carbonyl derivatives. It was demonstrated that the formation of the two possible regioisomers was fully triggered by both the R substituent onto the 2-amino-substituted carbonyl compounds and the ester function onto the oxoproline carbamate. Thus, in some cases, a complete regiocontrol for the Friedländer reaction could be attained.

\section{Introduction}

Natural or synthetic $N$-heterocyclic compounds containing a condensed quinoline ring system continue to attract the interest of both organic and medicinal chemists mostly due to their antitumor activities $[1,2]$. Among them, pyrrolo[3,4$b]$ quinolone I and pyrrolo[3,2-b]quinolone II are two backbones of important value which can be found in molecules of high biological interest (Figure 1). Indeed, pyrrolo[3,4b] quinolone I is a key constituent of the alkaloid camptothecin (CPT, 1), selective poison of DNA topoisomerase 1, and thus well known for its anticancer activities. Over the years, the synthesis or isolation of many analogues of CPT possessing a pyrrolo[3,4- $b]$ quinolone backbone, together with their biological evaluation, has been published [3]. For example, the alkaloids luotonin A (2a) and rosettacin (2b), belonging to the aromathecin family, were proved to exhibit important cytotoxicity demonstrating once again the great interest of this skeleton [4]. Pyrrolo[3,2-b] quinolone moiety II is the central core of the alkaloid cryptolepine (3) traditionally used as an antimalarial drug $[5,6]$. It was shown that this alkaloid was able to intercalate with DNA, prompting it as a potential chemotherapeutic agent [7]. Compounds 4 have been published recently and were tested successfully over different cancer types, highlighting their biological potential [8].

Interested for many years in the synthesis of aromathecins, we have devoted a lot of efforts for the development of short and efficient routes for the access to these skeletons $[9,10]$. Recently, we have shown that the total synthesis of rosettacin (2b) could be achieved in few steps using an aryl radical cyclization onto an enamide [11].

In this paper, the unprecedented access to both pyrrolo $[3,4-b]$ quinolone and pyrrolo[3,2-b]quinolone backbones $\mathbf{5}$ and $\mathbf{6}$ starting from oxoproline carbamate $\mathbf{8}$ using Friedländer reaction for the formation of the $\mathbf{C}$ ring is discussed (see lower part of Scheme 1). It is important to notice that very interesting works were published employing the Friedländer reaction for the synthesis of pyrrolo[3,4$b]$ quinolone and/or pyrrolo[3,2-b]quinolone backbones $[12,13]$. Nevertheless, to the best of our knowledge, this is the first time that this reaction is used with oxoproline carbamate 


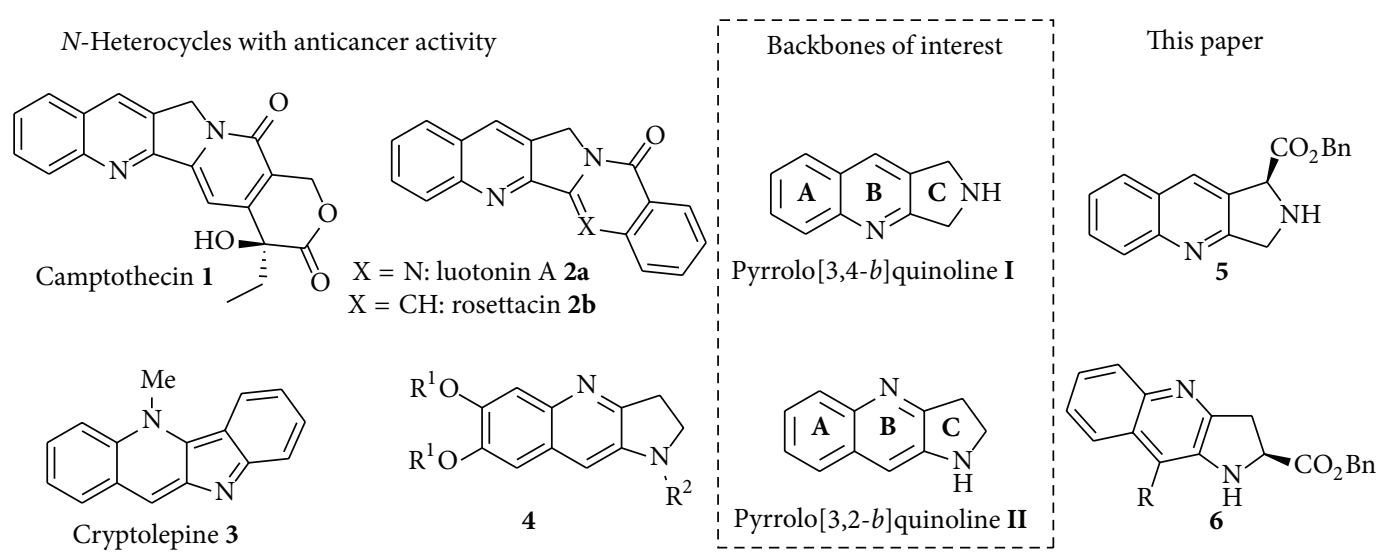

FIGURE 1: Interest of pyrrolo[3,4-b]quinolone and pyrrolo[3,2-b]quinolone backbones I and II.

Previous work
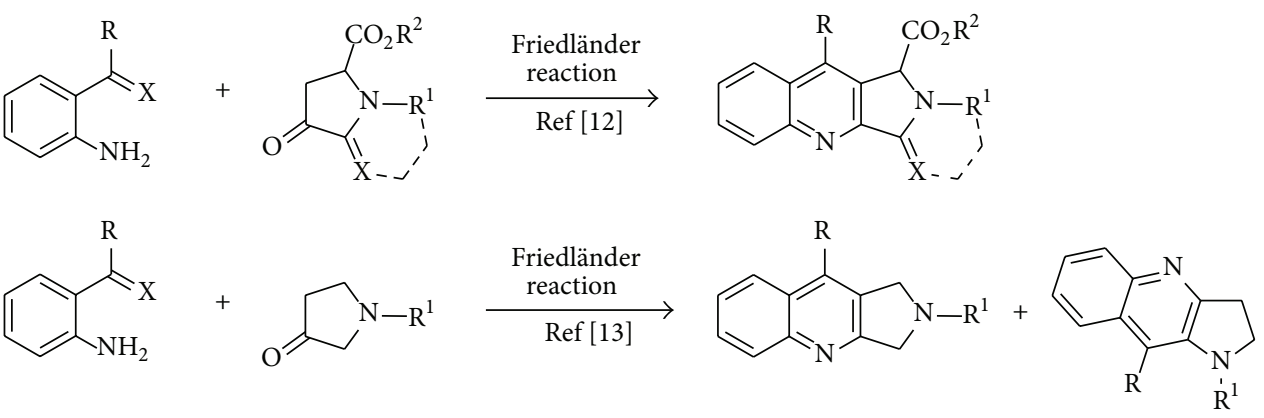

This work<smiles>[R]C(=[X])c1ccccc1N</smiles>

Role on the regiocontrol?<smiles>CC(C)(C)OC(=O)N1Cc2nc3ccccc3cc2C1C(=O)OC(=O)c1ccccc1</smiles>

5

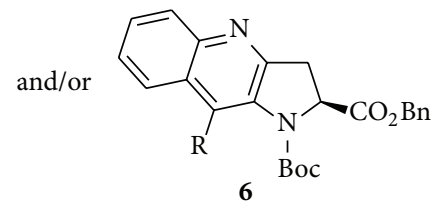

$\mathrm{R} \neq \mathrm{H}$, complete regiocontrol

SCHEME 1: Known strategies for the synthesis of pyrrolo[3,4-b]quinolone and pyrrolo[3,2-b]quinolone backbones and our retrosynthetic pathway to products 5 and 6 .

8 in order to study the influence of the ester function onto the regioselectivity of the process. In fact, we have shown that the formation of regioisomers $\mathbf{5}$ and/or $\mathbf{6}$ was triggered by both the $\mathrm{R}$ substituent onto 7 and the ester function onto 8. Indeed, when R group is not a hydrogen atom, only regioisomers 6 were obtained in good yield, demonstrating the dramatic role of these two groups. Moreover, besides the biological interest of the scaffolds $\mathbf{5}$ and $\mathbf{6}$, the access to these new proline derivatives could be of great importance in organocatalysis chemistry.

\section{Materials and Methods}

2.1. General Remarks. All commercially available starting materials were purchased from the Aldrich Chemical Co. or
Acros Organics Co. and were used without further purification. Solvents were dried, when necessary, by standard methods. All reactions were carried out under argon. The progress of the reactions was monitored by thin layer chromatography (TLC). Thin layer chromatography (TLC) was performed using silica gel analytical plates (F254) of $0.25 \mathrm{~mm}$ thickness. The detection on TLC plates was performed by UV light at 254 or $365 \mathrm{~nm}$ or using a permanganate or p-anisaldehyde revelator. Compositions of stereoisomeric mixtures were determined by ${ }^{1} \mathrm{H}$ NMR analysis of the crude mixture before any purification. Melting points $(\mathrm{Mp})$ were taken with a SMP10 capillary melting point apparatus (Stuart) and are uncorrected. The NMR spectra were recorded as solutions in $\mathrm{CDCl}_{3}$ at $200 \mathrm{MHz}\left({ }^{1} \mathrm{H}\right)$ and $50 \mathrm{MHz}\left({ }^{13} \mathrm{C}\right)$, respectively, and chemical shifts $(\delta)$ are expressed in ppm. 


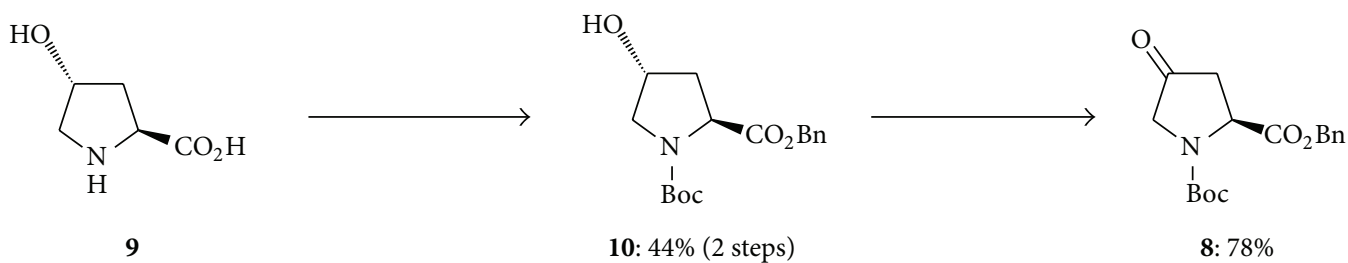

SCHeme 2: Synthesis of oxoproline carbamate 8.

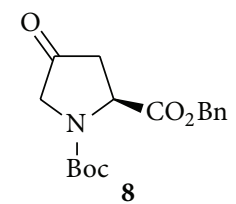

(1)<smiles>[R]C(=[X])c1ccccc1N</smiles>

(2) $\mathrm{CF}_{3} \mathrm{CO}_{2} \mathrm{H}$

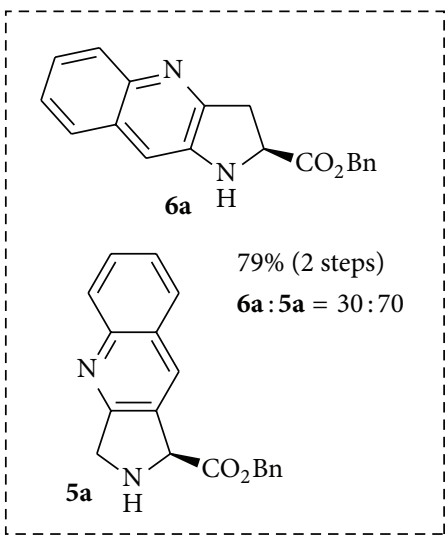

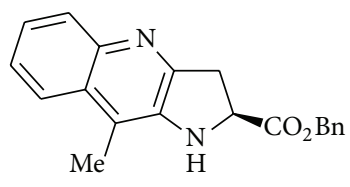

6b: $63 \%$ (2 steps)

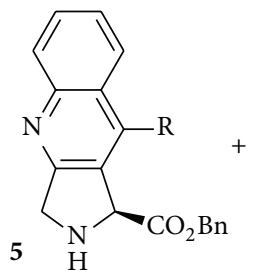<smiles>[R]c1c2c(nc3ccccc13)C[C@H](C(=O)OCc1ccccc1)N2</smiles>

Scheme 3: Access to pyrrolo[3,4-b]- and pyrrolo[3,2-b]quinolone derivatives 5 and 6 .

The assignments for compounds $\mathbf{8}$ and $\mathbf{1 0}$ matched those previously published [14].

2.2. General Procedure for the Synthesis of Compounds 5 and 6. The required aniline derivative $7(0.55 \mathrm{mmol}, 1.1 \mathrm{eq})$ and oxoproline carbamate 8 ( $160 \mathrm{mg}, 0.5 \mathrm{mmol}, 1 \mathrm{eq})$ were dissolved in freshly distilled toluene $(5 \mathrm{~mL})$. p-Toluenesulfonic acid (PTSA, $9.5 \mathrm{mg}, 0.05 \mathrm{mmol}, 0.1 \mathrm{eq}$ ) was then added. The mixture was stirred under reflux for 14 hours and the solvent was removed under vacuum. The crude mixture was dissolved in EtOAc $(20 \mathrm{~mL})$ and was then washed successively with a saturated aqueous solution of $\mathrm{NaHCO}_{3}(10 \mathrm{~mL})$ and brine $(10 \mathrm{~mL})$. The organic layer was dried over $\mathrm{MgSO}_{4}$ and concentrated under vacuum. The crude mixture was directly used in the next step without further purification.

The crude of the previous step was dissolved in freshly distilled $\mathrm{CH}_{2} \mathrm{Cl}_{2}(5 \mathrm{~mL})$ and trifluoroacetic acid (TFA, $0.37 \mathrm{~mL}, 10 \mathrm{eq}$ ) was then added. After one night of stirring at room temperature, the solvent was removed under vacuum. The crude mixture was dissolved in EtOAc $(20 \mathrm{~mL})$ and was then washed successively with a saturated aqueous solution of $\mathrm{NaHCO}_{3}(2 * 10 \mathrm{~mL})$ and brine $(10 \mathrm{~mL})$. The organic layer was dried over $\mathrm{MgSO}_{4}$ and concentrated under vacuum. The residue was then chromatographed on silica gel to provide the desired compound (typically, AcOEt/cyclohexane, $20: 80$ ).

\section{Results and Discussion}

The key oxoproline carbamate $\mathbf{8}$ was synthesized starting from commercially available trans-4-hydroxy-L-proline (9) using a modified version of the route reported by Qiu and Qing (Scheme 2) [14]. Starting material (9) was first converted in two steps, that is, Boc protection of the nitrogen atom and benzylation of the acid function, into the corresponding $\mathrm{N}$-Boc-benzyl ester 10 in $44 \%$ overall yield. Oxidation of the alcohol moiety was performed using PCC and led to the desired product 8 in a good $78 \%$ yield.

Friedländer condensations between oxoproline carbamate $\mathbf{8}$ and aniline derivatives 7 were carried out using classical procedure (Scheme 3) [15]. In order to facilitate the NMR spectra analysis, the Friedländer reaction was directly followed by Boc deprotection of the nitrogen atom of the pyrrolidine ring using trifluoroacetic acid. In the case of $\mathbf{7 a}$ (see lower part of Scheme 3), the two regioisomers $\mathbf{5 a}$ and $\mathbf{6 a}$ were formed in a good 79\% yield and in a 70:30 ratio. This regioselectivity is in accordance with the one observed by 


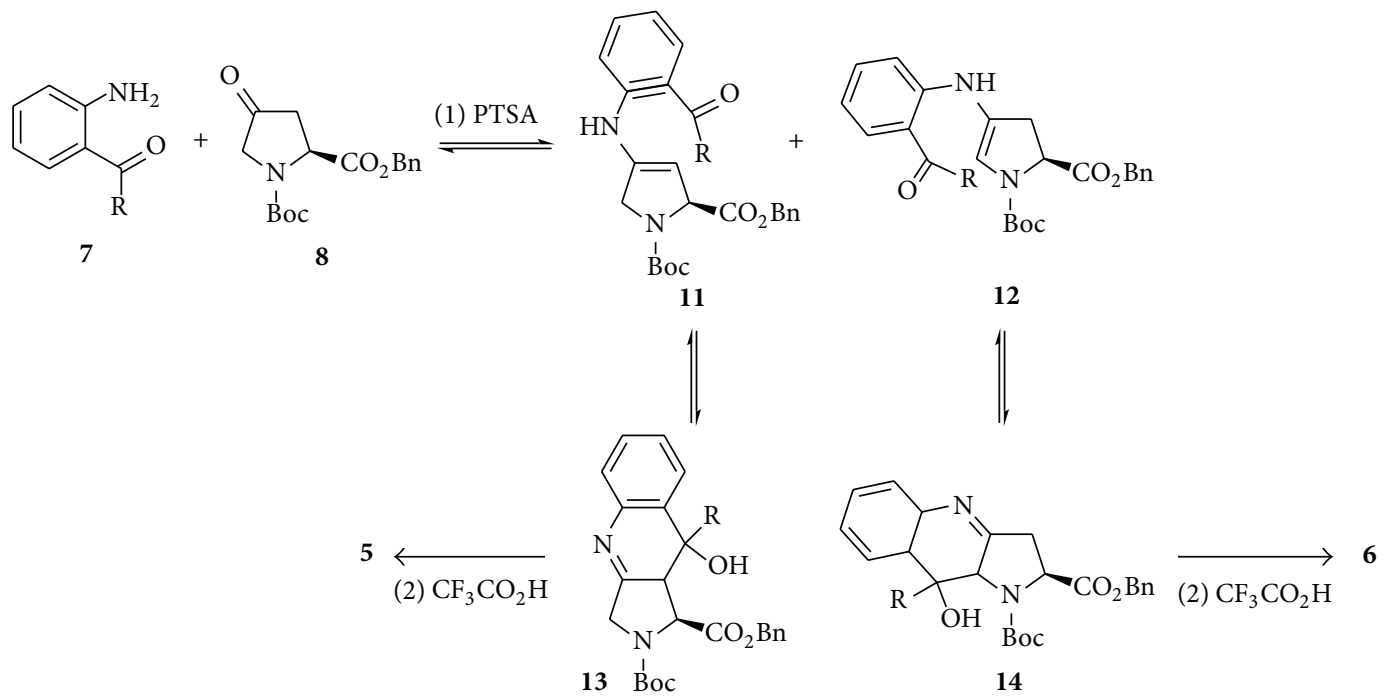

Scheme 4: Proposed mechanism for the Friedländer reaction leading to $\mathbf{5}$ and $\mathbf{6}$.

Akue-Gedu and coworkers for similar substrate [13]. Interestingly, when substrates $7 \mathbf{b}$ and $7 \mathbf{c}$ were employed, only regioisomers $\mathbf{6 b}$ and $\mathbf{6 c}$ were observed by ${ }^{1} \mathrm{H}$ NMR of the crude mixture prior to any purification. They were isolated after chromatographic purification in $63 \%$ and $58 \%$ yield, respectively.

The unprecedented high regioselectivity in favour of products $\mathbf{6}$ is not fully understood yet. Nevertheless, based on the mechanism commonly accepted for the Friedländer reaction [15], we propose the following mechanism (Scheme 4). In the presence of p-toluenesulfonic acid (PTSA), starting materials 7 and $\mathbf{8}$ led to the formation of the two possible enamines $\mathbf{1 1}$ and $\mathbf{1 2}$ in equilibrium with the corresponding tricyclic compounds $\mathbf{1 3}$ and $\mathbf{1 4}$. The observed regioselectivity could result from the steric hindrance and interactions between the R group and the ester function in intermediate $\mathbf{1 3}$ versus the $\mathrm{R}$ group and the Boc function in intermediate $\mathbf{1 4}$. This hypothesis will have to be confirmed by a computational analysis. Finally, when $\mathrm{R} \neq \mathrm{H}$, intermediate $\mathbf{1 4}$ was favoured and led to 6 by loss of water and Boc deprotection.

The structure of product $\mathbf{5 a}$ was deduced from its ${ }^{1} \mathrm{H}$ NMR and ${ }^{13} \mathrm{C}$ NMR spectral data and by comparison with similar structures $[12,13]$. For example, the ${ }^{1} \mathrm{H}$ NMR spectrum of 5a contained two doublets $(\delta=4.64$ and $4.40 \mathrm{ppm}$, $J=15.7 \mathrm{~Hz}$ ) for the two $\mathrm{CH}_{2}$ protons of the pyrrolidine ring confirming the presence of a stereogenic center.

(S)-Benzyl 2,3-Dihydro-1H-pyrrolo[3,4-b]quinoline-1-carboxylate $(\mathbf{5 a})$. This product was obtained by reaction between 8 and 7 a. $54 \%$ over 2 steps (AcOEt/cyclohexane, $20: 80$ ). ${ }^{1} \mathrm{H}$ NMR $\left(200 \mathrm{MHz}, \mathrm{CDCl}_{3}\right): 8.20-8.12(\mathrm{~m}, 2 \mathrm{H}), 7.76-7.65(\mathrm{~m}$, 2H), 7.55-7.47 (m, 1H), 7.37 (bs, 5H), 5.32-5.19 (m, 3H), 4.64 $(\mathrm{d}, J=15.7 \mathrm{~Hz}, 1 \mathrm{H}), 4.40$ (d, $J=15.7 \mathrm{~Hz}, 1 \mathrm{H}), 2.36$ (bs, $1 \mathrm{H}) .{ }^{13} \mathrm{C}$ NMR $\left(50 \mathrm{MHz}, \mathrm{CDCl}_{3}\right.$ ): 171.8, 163.6, 148.4, 135.1, 130.9, 129.7, $128.7,128.4,128.0,127.0,126.2,67.6,63.6,52.4$.

Moreover, 5a ${ }^{13} \mathrm{C}$ DEPT-135 NMR spectrum showed both the presence of the carbonyl carbon at $\delta=171.8 \mathrm{ppm}$ and the $\mathrm{CH}$ and $\mathrm{CH}_{2}$ carbons of the pyrrolidine ring at 63.6 and 52.4 ppm, respectively. In the case of the ${ }^{1} \mathrm{H}$ NMR spectrum for products 6 , they all displayed the same characteristic doublet of doublet for the two $\mathrm{CH}_{2}$ and $\mathrm{CH}$ proton of the pyrrolidine ring. For example, compound $\mathbf{6 b}$ exhibits a doublet of doublet $(J=9.4$ and $5.5 \mathrm{~Hz})$ for the $\mathrm{CH}$ at $4.58 \mathrm{ppm}$ and two doublet of doublet $(J=18.0$ and $9.4 \mathrm{~Hz}$ and $J=18.0$ and $5.5 \mathrm{~Hz}$ ) at 3.68 and $3.54 \mathrm{ppm}$, respectively.

(S)-Benzyl 9-Methyl-2,3-dihydro-1H-pyrrolo[3,2-b]quinoline2 -carboxylate $(\mathbf{6} \boldsymbol{b})$. This product was obtained by reaction between 8 and $7 \mathbf{b}$. $63 \%$ over 2 steps (AcOEt/cyclohexane, 20 : 80). ${ }^{1} \mathrm{H}$ NMR (200 MHz, $\mathrm{CDCl}_{3}$ ): 7.92-7.85 (m, 1H), 7.837.75 (m, 1H), 7.49-7.40 (m, 2H), 7.36 (bs, 5H), $5.20(\mathrm{~s}, 2 \mathrm{H})$, 4.59 (bs, $1 \mathrm{H}), 4.58(\mathrm{dd}, J=9.4$ and $5.5 \mathrm{~Hz}, 1 \mathrm{H}), 3.68(\mathrm{dd}, J=$ 18.0 and $9.4 \mathrm{~Hz}, 1 \mathrm{H}), 3.54(\mathrm{dd}, J=18.0$ and $5.5 \mathrm{~Hz}, 1 \mathrm{H}), 2.42$ (s, 3H). ${ }^{13} \mathrm{C} \mathrm{NMR}\left(50 \mathrm{MHz}, \mathrm{CDCl}_{3}\right.$ ): 173.3, 154.3, 143.8, 139.9, 135.2, 129.0, 128.8, 128.7, 128.4, 126.1, 125.4, 122.3, 117.6, 67.6, 57.8, 35.7, 12.1. $[\alpha]_{\mathrm{D}}{ }^{20}+19.2\left(c=0.61, \mathrm{CHCl}_{3}\right)$.

Finally, its ${ }^{13} \mathrm{C}$ DEPT-135 NMR spectrum also confirmed the presence of the carbonyl carbon at $\delta=173.3 \mathrm{ppm}$ when the $\mathrm{CH}$ and $\mathrm{CH}_{2}$ carbons were observed at 57.8 and $35.7 \mathrm{ppm}$, respectively.

\section{Conclusion}

The regioselective access to both pyrrolo[3,4-b]quinolone and pyrrolo[3,2- $b]$ quinolone backbones was achieved in 5 steps and good yield starting from commercially available trans-4-hydroxy-L-proline. The Friedländer condensation between 2-amino-substituted carbonyl compounds and an oxoproline carbamate was efficient and allowed the formation of the desired products in good yield. More importantly, and to the best of our knowledge, this is the first time that this reaction between these two partners was studied. We have shown that the access to the two possible regioisomers was controlled by both the $\mathrm{R}$ substituent onto 
the 2-amino-substituted carbonyl derivatives and the ester function of the oxoproline carbamate. This synthetic strategy could be used in the future to regioselectively access either the pyrrolo[3,4-b]quinolone or pyrrolo[3,2-b]quinolone backbones by modulating substituents onto Friedländer reaction's partners. This reactivity is already under investigation and the results will be published in due course.

\section{Conflict of Interests}

The authors declare that there is no conflict of interests regarding the publication of this paper.

\section{Acknowledgments}

The authors thank the "Fédération de Chimie": FR CNRS 3038 (INC3M), the "réseau CRUNCH", and the URCOM laboratory for their financial support.

\section{References}

[1] C. Karthikeyan, C. Lee, J. Moore et al., "IND-2, a pyrimido $\left[1^{\prime \prime}, 21^{\prime \prime}: 1,5\right]$ pyrazolo[3,4-b]quinoline derivative, circumvents multi-drug resistance and causes apoptosis in colon cancer cells," Bioorganic \& Medicinal Chemistry, vol. 23, no. 3, pp. 602-611, 2015.

[2] D. B. Khadka and W.-J. Cho, "3-Arylisoquinolines as novel topoisomerase i inhibitors," Bioorganic and Medicinal Chemistry, vol. 19, no. 2, pp. 724-734, 2011.

[3] Y. Pommier, "DNA topoisomerase I inhibitors: chemistry, biology, and interfacial inhibition," Chemical Reviews, vol. 109, no. 7, pp. 2894-2902, 2009.

[4] M. A. Cinelli, A. E. Morrell, T. S. Dexheimer et al., "The structure-activity relationships of A-ring-substituted aromathecin topoisomerase I inhibitors strongly support a camptothecin-like binding mode," Bioorganic and Medicinal Chemistry, vol. 18, no. 15, pp. 5535-5552, 2010.

[5] O. Onyeibor, S. L. Croft, H. I. Dodson et al., "Synthesis of some cryptolepine analogues, assessment of their antimalarial and cytotoxic activities, and consideration of their antimalarial mode of action," Journal of Medicinal Chemistry, vol. 48, no. 7, pp. 2701-2709, 2005.

[6] C. W. Wright, J. Addae-Kyereme, A. G. Breen et al., "Synthesis and evaluation of cryptolepine analogues for their potential as new antimalarial agents," Journal of Medicinal Chemistry, vol. 44, no. 19, pp. 3187-3194, 2001.

[7] K. Bonjean, M. C. De Pauw-Gillet, M. P. Defresne et al., "The DNA intercalating alkaloid cryptolepine interferes with topoisomerase II and inhibits primarily DNA synthesis in B16 melanoma cells," Biochemistry, vol. 37, no. 15, pp. 5136-5146, 1998.

[8] H.-J. Kim, M. I. El-Gamal, Y. S. Lee, and C.-H. Oh, "Synthesis and preliminary cytotoxicity evaluation of new diarylamides and diarylureas possessing 2,3-dihydropyrrolo[3,2-b]quinoline scaffold," Bulletin of the Korean Chemical Society, vol. 34, no. 8, pp. 2480-2486, 2013.

[9] F. Pin, S. Comesse, M. Sanselme, and A. Daïch, "A domino $\mathrm{N}$-amidoacylation/aldol-type condensation approach to the synthesis of the topo-I inhibitor rosettacin and derivatives," Journal of Organic Chemistry, vol. 73, no. 5, pp. 1975-1978, 2008.
[10] F. Pin, S. Comesse, and A. Daïch, "Association of intramolecular furan Diels-Alder reaction and $\mathrm{N}$-acyliminium alkylation for the synthesis of pentacyclic precursor of aromathecins," Synlett, pp. 3214-3218, 2009.

[11] L. El Blidi, A. Namoune, A. Bridoux et al., "Expeditious synthesis of the topoisomerase I inhibitors isoindolo[2,1$b$ ]isoquinolin-7 $(5 \mathrm{H})$-one and the alkaloid rosettacin based on aryl radical cyclization of enamide generated by using $\mathrm{N}$ acyliminium chemistry," Synthesis, vol. 47 , no. 22 , pp. $3583-$ 3592, 2015.

[12] T. Brunin, L. Legentil, J.-P. Hénichart, and B. Rigo, “Towards new camptothecins. Part 3: synthesis of 5-methoxycarbonyl camptothecin," Tetrahedron, vol. 62, no. 17, pp. 3959-3968, 2006.

[13] R. Akue-Gedu, P. Gautret, J.-P. Lelieur, and B. Rigo, "An improved synthesis of methyl 1,3-dihydro- $2 \mathrm{H}$-pyrrolo[3,4b] quinoline-2-carboxylate," Synthesis, no. 21, pp. 3319-3322, 2007.

[14] X.-L. Qiu and F.-L. Qing, "Practical synthesis of Boc-protected cis-4-trifluoromethyl and cis-4-difluoromethyl-L- prolines," Journal of Organic Chemistry, vol. 67, no. 20, pp. 7162-7164, 2002.

[15] J. Marco-Contelles, E. Pérez-Mayoral, Abdelouahid Samadi, M. D. C. Carreiras, and E. Soriano, "Recent advances in the Friedländer reaction," Chemical Reviews, vol. 109, no. 6, pp. 2652-2671, 2009. 

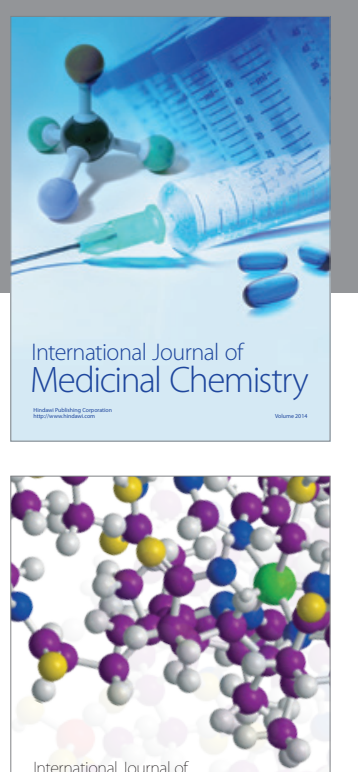

Carbohydrate Chemistry

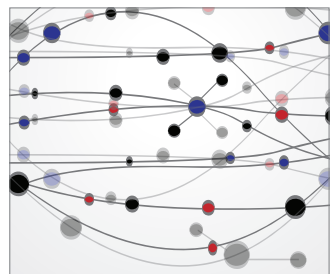

The Scientific World Journal
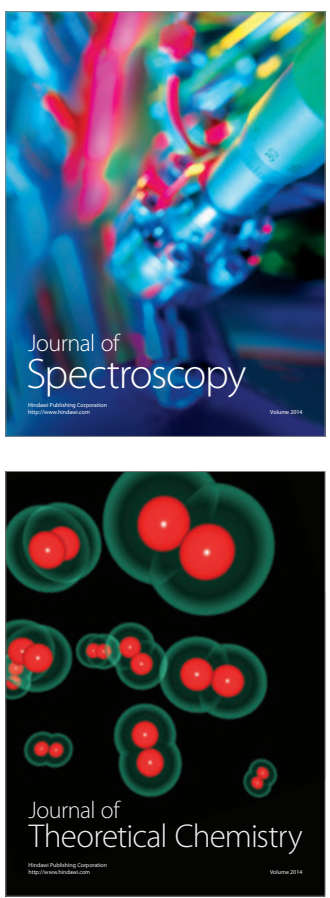
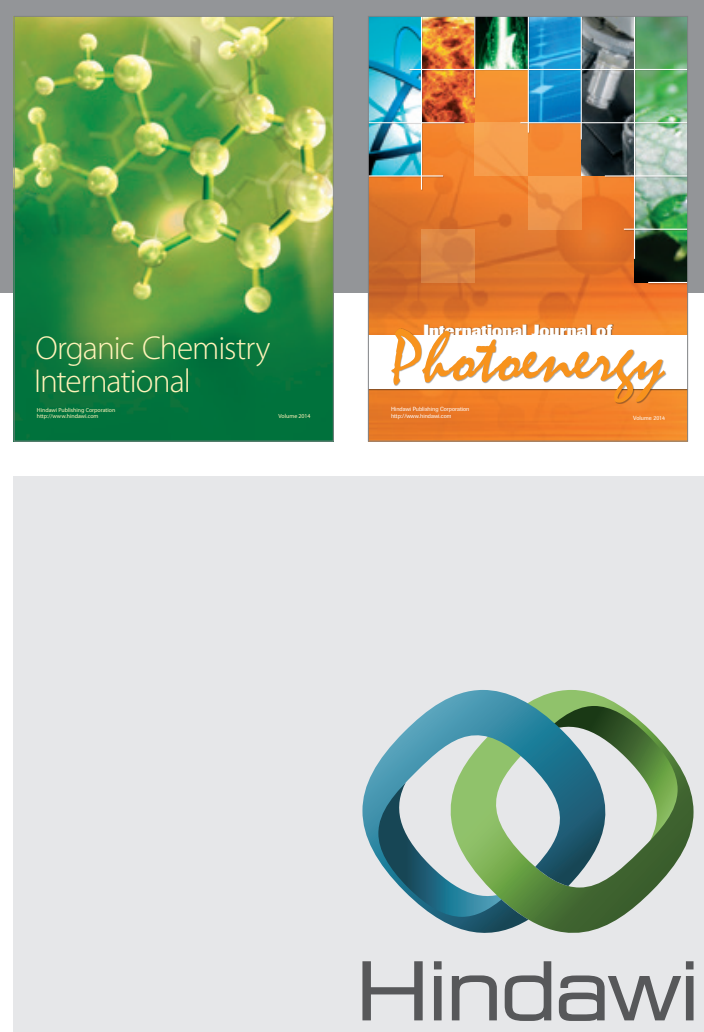

Submit your manuscripts at

http://www.hindawi.com

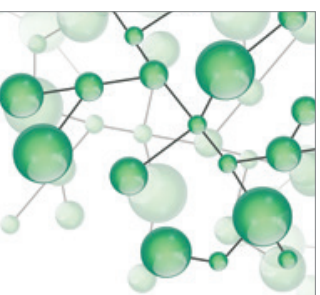

International Journal of

Inorganic Chemistry

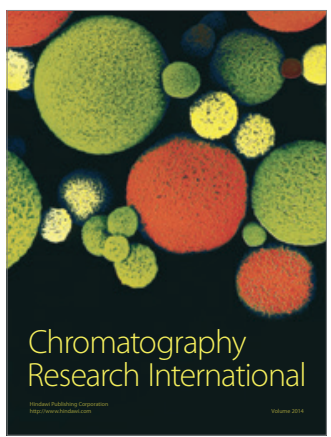

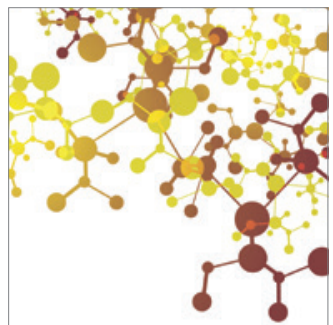

Applied Chemistry
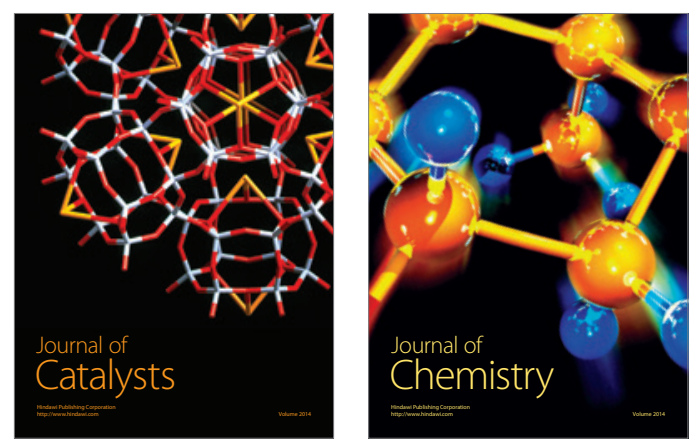
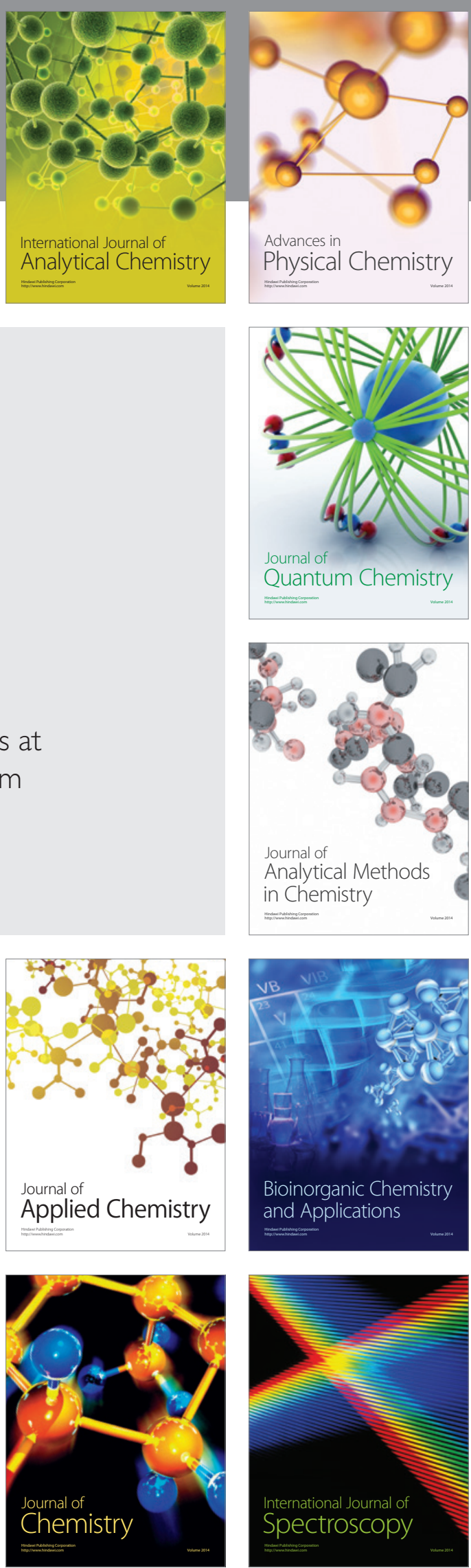